\title{
Predictors of Migration in an HIV Hyper-Endemic Rural South African Community: Evidence From a Population-Based Cohort (2005-2017)
}

\section{Armstrong Dzomba ( $\sim$ Edzombaarmstrong625@gmail.com )}

University of the Witwatersrand

Hae-Young Kim

New York University Grossman School of Medicine

Andrew Tomita

University of KwaZulu-Natal

Alain Vandormael

University of Heidelberg

Kaymarlin Govender

University of KwaZulu- Natal

Frank Tanser

University of Lincoln

\section{Research Article}

Keywords: Migration, Migration incidence, Transients and Migrants, Antiretroviral Therapy, Human Immunodeficiency Virus

Posted Date: January 3rd, 2022

DOI: https://doi.org/10.21203/rs.3.rs-1152226/v1

License: (c) (i) This work is licensed under a Creative Commons Attribution 4.0 International License.

Read Full License 


\section{Abstract}

Globally, South Africa ranks worst for people living with HIV (PLHIV) and the unique legacy of internal labour migration continues to be a major driver of the regional epidemic, interrupting treatment-asprevention efforts. The study examined levels, trends, and predictors of migration in rural KwaZulu-Natal Province, South Africa, using population-based surveillance data from 2005 through 2017. We followed 69604 adult participants aged 15-49 years and recorded their migration events (i.e., out-migration from the surveillance area) in 423038 person-years over 525397 observations. Multiple failure Cox-regression models were used to measure the risk of migration by socio-demographic factors: age, sex, educational status, marital status, HIV, and community antiretroviral therapy (ART) coverage. Overall, $69 \%$ of the population cohort experienced at least one migration event during the follow-up period. The average incidence rate of migration was 9.96 events and 13.23 events per 100 person-years in women and men, respectively. Migration rates declined from 2005 to 2008 then peaked in 2012 for both women and men. Adjusting for other covariates, the risk of migration was 3.4-times higher among young women aged 2024 years compared to those aged $\geq 40$ years (adjusted Hazard Ratio [aHR] $=3.37,95 \%$ Confidence Interval [CI]: 3:19-3.57), and 2.9-times higher among young men aged 20-24 years compared to those aged $\geq 40$ years $(\mathrm{aHR}=2.86,95 \% \mathrm{Cl}: 2.69-3.04)$. There was a $9 \%$ and $27 \%$ decrease in risk of migration among both women $(\mathrm{aHR}=0.91,95 \% \mathrm{Cl}: 0.83-0.99)$ and men (aHR=0.73, 95\% $\mathrm{Cl} 0.66-0.82)$ respectively per every $1 \%$ increase in community ART coverage. Young unmarried women including those living with HIV, migrated at a magnitude similar to that of their male counterparts, and lowered as ART coverage increased over time, reflecting the role of improved HIV services across space in reducing out-migration. A deeper understanding of the characteristics of a migrating population provides critical information towards identifying and addressing gaps in the HIV prevention and care continuum in an era of high mobility.

\section{Introduction}

South Africa has the highest number of people living with HIV (7.2 million) and runs the world's largest HIV treatment programme (4.4 million) [1]. Over the last decade, the rapid scale-up and increasingly wide coverage of antiretroviral therapy (ART) led to large declines in AIDS-related deaths and new infections [2,3], with the latter being almost halved between 2011-2016 [4,5]. However, HIV incidence rates continue to remain high, with an estimated 240000 adults newly infected in 2019 alone [1]. Widespread internal mobility and frequent geographical relocations have been strongly linked with intensified HIV transmission, risky sexual behavior and interruption of care continua among people living with HIV (PLHIV) [6-24], sustaining the epidemic. South Africa has exceptionally high internal migration rates compared to other countries in sub-Saharan Africa (SSA) [25], having significantly increased since the advent of democracy, propagating different forms of movement and changing the profiles of migrants [26-28]. In rural KwaZulu-Natal Province communities, high out-migration flows to urban locations have been observed [29] and linked to better amenities and employment opportunities in larger cities [29]. As 
such, a previous study reported that $\sim 64 \%$ of the adult resident population had migrated at least once between 2005 and 2011 [30], demonstrating the persistence of movement outside the rural households.

The current HIV treatment and prevention landscape builds on existing evidence that population-level reductions in the transmission of HIV could be achieved by leveraging expanded coverage of services [1]. The 95-95-95 targets aimed to have 95\% of people living with HIV (PLHIV) know their status, of whom $95 \%$ can access ART, and of whom 95\% are virally suppressed by 2030 as an indication of their successful engagement in care [1]. Universal voluntary HIV counselling and testing, accompanied by immediate initiation of antiretroviral therapy (ART) for all those diagnosed HIV-infected, as well as Universal Test and Treat (UTT), has been the principal strategies through which the 95-95-95 targets are to be achieved. Despite being on track to achieve the first and last 95 in South Africa, only approximately $70 \%$ of PLHIV were receiving ART in 2020 , with substantial variations by age and sex among those virally suppressed [31]. Moreover, efforts to increase ART coverage have been a challenge for migrant populations to be retained in the HIV care continuum [9]. Examining trends, incidence and predictors of mobility is an essential first step towards identifying impactful migrant-sensitive HIV prevention and care interventions.

Motivated by lack of evidence, there is need to deepen our understanding of the mobility patterns and potential drivers of migration for PLHIV in light of large-scale treatment-as-prevention HIV interventions, such as the UTT currently underway in South Africa. Unfortunately, most HIV interventions fail to appropriately account for the spatial and temporal nature of mobility [32,33]. For this reason, it is crucial to fill this gap in knowledge and investigate the socio-demographic, clinical and community predictors of migration for intervention target/profile setting, as highly mobile individuals are well known to encounter test/treatment access and retention challenges that can potentially jeopardize the chance of ending the epidemic and preventing further HIV drug resistance [25,32] in South Africa. In this study, we quantified the role of socio-demographic, clinical and community predictors against out-migration incidence using one of Africa's largest population-based cohorts in an HIV hyper-endemic rural community in South Africa among 70,000 individuals, both HIV-positive and negative. In particular, we focused on age, sex, educational status, marital status, HIV and community antiretroviral therapy (ART) coverage, and measured the incidence rates per year.

\section{Methods}

\section{Study Design}

We analyzed data from the population-based longitudinal surveillance system conducted by the Africa Health Research Institute (AHRI), which is located in the rural uMkhanyakude District of northern KwaZulu-Natal Province. The surveillance includes members of all households located in the $438 \mathrm{~km}^{2}$ surveillance area, with a population of approximately 100000 resident and non-resident members from 11000 households [3]. AHRI has collected comprehensive socio-demographic information since 2000 on household residencies, mobility patterns and migration, while HIV survey data are available from 2004. 
ART information is regularly updated on patient records in local primary health care (PHC) clinics and retrievable from the electronic patient management system (Tier.Net) database. Surveys capturing demographic events that can change the structure of the household, such as births, deaths and migrations from key household informants every 4-6 months, were conducted by trained fieldworkers. Data on other socio-economic, health exposures and outcomes, such as education and HIV status, were collected annually since 2004, while ART information was captured from local clinics' HIV treatment and care program, as highlighted above. Household and individual surveys are linked longitudinally to each other and over time through unique individual and household identification. For HIV surveillance, eligible participants aged 15-years and older are interviewed in private by the same fieldworkers, who also extract blood from consenting participants by finger-prick for annual HIV testing.

This community is characterized by frequent migration (32\% of women and $38 \%$ of men were nonresident in 2008), and high levels of residential instability, with $33 \%$ of those regarded as household members in the surveillance area not residing within the registered households [34]. Local employment is scarce, and residents often migrate for work outside the area. Levels of mobility in the region have risen in recent decades, aligned with rapid socio-economic transformations and the increased labour participation of women. For example, economically active adult women increased from $31 \%$ to $41 \%$ between 2008 and 2011 in those of working age [13]. Circular migration predominates in this setting, with individuals migrating repeatedly between rural areas, semi-urban towns and the rural perimeters of cities. Women are somewhat more likely than men to undertake any form of migration, although sex differentials in migration trends differ by migration distances [29].

Other characteristics of the surveillance area include low marital rates (i.e. only $20 \%$ of conjugal couples among those 20-29 years were married), late marriages, high partnership dissolution rates among older women and younger men [35], multiple sexual partnerships as well as by poor knowledge and disclosure of HIV status [34]. KwaZulu-Natal Province bears the largest HIV burden in South Africa, with adult HIV prevalence in this region being $36 \%$ in 2017 [36] and disproportionate provision of HIV services particularly in poorer settings [37-39]. ART coverage increased rapidly since 2004, primarily via nurse-led public sector ART programs. The expanded scale-up of ART increased its coverage from $2.1 \%$ in 2005 to $24.6 \%$ in 2010 , and to $50.6 \%$ in 2017 among HIV-positive women, and from $1.5 \%$ in 2005 to $21.4 \%$ in 2010 and $38.4 \%$ in 2017 among HIV-positive men [4].

\section{Patient and public involvement}

AHRI has been working with the communities of the 11000 households of the study site since 2000, with close consultation of the population as well as their political and traditional hierarchies. All study consecutive waves are discussed with the Community Advisory Board (CAB) and representatives of all villages before each census launch. Data collection (i.e., including HIV testing in 2003 and beyond) was based on existing knowledge of the HIV burden in the general population of this community, and discussions with the CAB serving as an input to the study design. The recruitment of participants was conducted after community engagement, i.e., informing communities (a meeting in each village) about 
the study. Finally, after each census is completed, the key findings are communicated back to the community through routine meetings with representatives of local authorities and Community Roadshows. However, for this study, neither patients nor the public were not involved the design, or conduct, or reporting, or dissemination plans of the research. All methods were carried out in accordance with relevant guidelines and regulations and informed consent was obtained from all the study participants.

\section{Ethics statement}

The Biomedical Research Ethics Committee of the University of KwaZulu-Natal (BREC) Durban, South Africa, gave full ethics approval for this study Ref. no. BE283/17.

\section{Migration events}

The primary outcome of the study was the outgoing external migration among women and men aged 12 years or older. Our cohort comprised of individuals who were residents when first observed and had previously moved out and back into the study area into the AHRI setting between 2004 and 2017. We defined migration as a movement out of the surveillance area (i.e. out-migration), and categorised a migrant as a person who had experienced an out-migration event from the study area and a non-migrant as having no migration history. Fieldworkers routinely collect migration history data for migrants and non-migrants from key household informants, including details such as place of destination and date on which every migration event occurred. These migration events lasted varying periods of time over the course of observation. An explicit focus on out-migration enabled us to examine the pre-migration characteristics of mobile adults and assess one important end (origin) of the migration axis in a rural community with high cyclical livelihood migration to urban destinations.

\section{Predictors}

With the exception of sex, time-varying risk factors included: age $(15-19 ; 20-24 ; 25-29 ; 30-34 ; 35-39 ; \geq 40$ years); educational attainment (no schooling; primary, secondary, tertiary, unknown educations status); marital status (single, married (monogamous/polygamous), separated or divorced, or unknown); HIV status (HIV negative and positive), antiretroviral therapy (a continuous variable) and percentage of community coverage. ART coverage, defined as the proportion of individuals HIV positive receiving ART for each community within the AHRI study site as previously described [3].

The marital status and educational attainment variables had missing data for $15 \%$ and $18.7 \%$ of the records, respectively. Response rates for HIV were low and prone to missing data, and between 2005 and $2017,48.7 \%$ of total records had no data on HIV status. Evidence from the study area found substantially high participation rates over time but lower over single wave surveys, which is an expected outcome $[39,40]$. To help address missingness of data, we categorized values as missing per each variable, thus retaining data for all individuals across different models.

\section{Statistical analysis}


First, we determined the prevalence of residency and non-residency among both women and men between 2005 and 2017 by calculating mid-year frequencies and percentages for residency status by sex (i.e. period of time during which an individual was either present or absent in the surveillance area).

Secondly, we estimated migration incidence rates per each year and socio-demographic and health/clinical factors. Thirdly, we fitted Anderson-Gill models to estimate hazard ratios for the association between the risk factors (age, sex, education status, marital status, HIV status, community ART coverage) and out-migration events. We repeated the same analysis to generate hazard ratios stratified by sex, as past studies have shown that male and female have different motivations to of migrate [19-20, 30]. All models (univariate and multivariate) were fitted employing a counting notation as described by Lin and Zelterman [41]. To account for clustering of observations within each individual, and to control for follow-up time of individuals, we estimated robust standard errors in the analysis. The cox models fitted a unique baseline hazard function per each successive migration event. In addition, we performed sensitivity analyses (i.e. complete case analysis and repeating the statistical stratified by HIV status categories) to diagnose and adjust for selection effects, which are described in the results section. Analyses were performed using Stata 14.0 software (StataCorp, College Station, Texas, USA).

\section{Results}

\section{Residency}

Table 1 presents the data for the resident and non-resident adult study participants between 2005 and 2017. For each year, more than $24 \%$ of both women and men were non-residents in the surveillance area. The proportion of non-residents was lower in women than in men, although non-residence similarly increased from $24 \%$ to $33 \%$ in women and $29 \%$ to $40 \%$ in men over time.

\section{Out-migration rates: $2005-2017$}

Crude annual migration rates for the observation period are presented in Table 2 and Fig 1, ranging from 9.37 to 13.17 per 100 PY for both males and females. Overall, migration rates were high and fluctuating from 2005 to peak until 2009, after which they rose steadily to secondary peaks in 2010 and 2012, beyond which they declined.

Highlighting other important data, the sex-specific trends of migration rates showed slightly bimodal patterns (Figure 1), with the migration rates in women and men being similar across the years under observation. While migration was slightly lower in women than men, their primary peaks were smoother and showed a sharper slope than the men, particularly between 2008 and 2012.

\section{Incidence of out-migration: socio-demographic and health factors}

Over the duration of the study (2005-2017), the crude migration rate was 11.29 events (95\% confidence interval Cl 11.19 - 11.39) per 100 person-years (47 772) events in 423038 person-years of follow-up. Stratified by sex, the migration incidence rate was 9.96 events ( $95 \% \mathrm{Cl} 9.84-10.09)$ per 100 person-years 
(24 990 migration events in 250833 person-years of follow-up) in women, while the rate was 13.23 events (95\% Cl 13.06 - 13.40) per 100 person-years (22 782 migration events in 172205 person-years of follow-up) among men (Table 3). The incidence rate for migration among HIV negative individuals was 4.14 events $(95 \% \mathrm{Cl} 4.04-4.25)$ per 100 person-years, while PLHIV had 8.86 events per $(95 \% \mathrm{Cl} 8.62-$ 9.12) per 100 person-years, and there were 17.15 events $(95 \% \mathrm{Cl} 16.98-17.33)$ among those with unknown HIV-status.

The age-sex-specific distribution of migration rates was similar in both women and men across the years under observation, with the highest incidence rates among young adults aged 20-24 years (Figure 2), which declined overall at ages $>25$ years.

\section{Survival data description and summary}

Over the course of the study (2005-2017), a total of 47802 out-migration events accrued in 423038 person-years of follow-up for 69604 participants in the cohort. Nearly $69 \%$ of all study participants had at least one migration event over 525397 observations. The mean follow-up time was 4.3 years (SEM 0.01) per individual, while the median number of migration events per person was four (IQR 2-7), ranging from 1 to 14 . The median time to migration by HIV status was 5.9 years $(95 \% \mathrm{Cl} 5.8-6.1)$ in PLHIV and 3.1 years $(95 \% \mathrm{Cl} 3.0-3.1)$ in those with unknown HIV status.

Table 4 shows the Andersen-Gill Model regression results for predictors of external migration events, with increased potential being associated with being aged 20-24 years (adjusted hazard ratio [aHR]=3.11, $95 \% \mathrm{Cl} 2.99-3.24)$ and $25-29$ years (aHR=2.30, 95\% $\mathrm{Cl} 2.20-2.40)$ compared to 40 years and older. Individuals who were single had a two times higher hazard of external migration than those who were married (aHR=2.28, 95\% $\mathrm{Cl} 2.15-2.41)$. Community ART coverage was among the most important factors significantly associated with migration in both the unadjusted and adjusted models. The risk of migration was $59 \%$ higher per every $1 \%$ increment in community ART coverage (HR=1.59, $95 \% \mathrm{Cl} 1.49-$ 1.69 ) and $16 \%$ lower per every $1 \%$ increment in community ART coverage (aHR=0.84, 95\% $\mathrm{Cl} 0.79-0.91)$.

Table 5 shows the results for the analyses stratified by gender, with out-migration being three times higher among women aged $20-24$ years (aHR=3.37, 95\% $\mathrm{Cl} 3.19-3.57$ ) compared to those aged $\geq 40$ years, while for men, those aged 20-24 years were 2.9 times more likely to migrate compared to those aged $\geq 40$ years. Nearly all covariates, including sex, age, education and marital status, were significantly associated with migration in the unadjusted and adjusted models for both women and men. HIV and ART status were strongly associated with the migration incidence among both women and men. Women who were HIV positive were 2.4 times more likely to migrate, compared to HIV-negative individuals in the unadjusted model, and such hazard remaining significant in the multivariate model (aHR=2.44, $95 \% \mathrm{Cl}$ 1.58-1.77). Similarly, the hazard of migration was 2.5-times higher (aHR=2.54,95\% $\mathrm{Cl} 2.36-2.73$ ) among HIV positive than HIV negative women. In separate models for women (aHR=4.18, 95\% Cl $4.03-4.34)$ and men $(\mathrm{aHR}=2.44,95 \% \mathrm{Cl} 3.89-4.23)$, migration risk increased by more than 4-times for those who were HIV positive compared to those who were negative. Community ART coverage was among the most important factors significantly associated with migration in both the unadjusted and adjusted models. 
Every $1 \%$ increase in community ART coverage lowered migration among women (aHR=0.91, 95\% Cl: 0.83 - 0.99) and men (aHR=0.73, 95\% Cl $0.66-0.82)$.

Based on the results from the complete case analysis (i.e. limiting analysis to non-missing data of variables relevant variables), the effects of socio-demographic characteristics (age and education status) on the migration risk profiles were similar to the estimates with the models in Tables 4 and 5 covariate information (Tables S2, S3). Similarly, in other sensitivity analyses, migration hazard by unknown HIV status and individuals with HIV positive and HIV negative status were comparable with the main models. The aHR for ages 20-24 and 25-29 compared to 40+ were 1.86; 3.33 for those HIV positive, 1.91; 2.88 for those with unknown HIV status, and 3.52; 4.78 for those HIV negative (S4-S6).

\section{Discussion}

In a rural South African community, between 2005 and 2017, we found that out-migration rates remained consistently high, with variance by sex. The risk of migration was three times higher among young adults (20-24 years) compared to older adults $\geq 40$ years, and two times higher among unmarried compared to married women and men. Notably, PLHIV had a two-fold increased hazard of migration when compared to HIV-negative men and women. However, increased community ART coverage lowered migration risk by $9 \%$ in women and $27 \%$ in men. These findings reflect a necessary focus on the context of mobility in SSA, a reality often overlooked in the development HIV treatment and prevention programs.

The socio-demographic profiles of migrating in our study were in keeping with the commonly held image of migrants from prior research in SSA. The high proportion of young women and men of working age with secondary education among migrants may reflect the persistence of historical labour-related mobility from rural to urban settings to seek greater employment opportunities [42-46]. Moreover, transition into early adulthood is an important life-course marker that is synonymous with establishing independent adult status, and often requires out-migration [47-48]. Other qualitative evidence highlights the complex interplay of motivations for young people to move within contexts of high HIV-risk in pursuit of economic opportunity [48]. Migration is typically prompted by either a desire or need to seek further education and to attain economic and social 'independence'. As such, migration may be involuntary, such as to escape from inadequate access to employment opportunities or the burden of not contributing to the family.

Beyond individual characteristics, meso- and macro-level factors are often important considerations for change of residence for PLHIV. There is evidence that in the context of limited treatment, an HIV diagnosis increases external migration as individuals move either to avoid social stigma from their communities or seek better palliative care elsewhere [20,50-51]. Previously, out-migrants from the study area (likely to urban areas with specialized HIV related services) had a lower risk of dying from AIDS compared to residents [19], signaling the association of movements outside poor communities with better health outcomes for PLHIV. Fortunately, in 2014, the UTT interventions and accompanying 95-9595 targets in KwaZulu-Natal Province and elsewhere were implemented, where universal roll-out of HIV 
services and antiretroviral therapy commenced for consenting adults and PLHIV, an estimated $70 \%$ in KZN are currently accessing therapy [52]. The wider coverage of ART in this community lowered migration, after adjusting for the key socio-demographic-clinical variables, possibly demonstrating alleviated problems related to the improved geographic accessibility of HIV services.

Our findings highlight the need to intensify the engagement and retention of migrants in effective combinations of HIV prevention and care programs in the era of ART. That ART coverage reduced migration may be illustrative of successful engagement to care in local clinics among those living with HIV, while increased mobility for PLHIV has implications for high onward transmission. We therefore echo others 'recommendations that mobile populations may benefit from novel models of differentiated care that simplify and adapt HIV services across the cascade for PLHIV and to decongest the health system $[33,53]$. These models include patient-led community adherence groups, sexual networks $[54,55]$, healthcare worker-managed groups, fast-track or multi-month drug scripting, mobile outreach, interventions optimized to seasonal migration patterns [54] and community drug distribution points (e.g. pharmacy-based refills). Importantly, these models can be facilitated by an acute awareness of the needs of mobile women and men living with HIV, holding the promise for engaging and retaining these populations who struggle to fit their needs to the requirements of community/clinic-based HIV care systems. Beyond social and structural interventions, mobile populations may benefit from improved therapeutic technologies, such as long-acting ART regimens, which should be accompanied by extending their coverage into communities and key migration destinations, including transit hubs [57]. Recognizing that migrants are increasingly young, unmarried and female, approaches sensitive to age, privacy and gender, such as self-testing kits [56-57] and pre-exposure prophylaxis kits [57-58], should be scaled up to aid HIV epidemic control.

The strengths of our study include the follow-up of more than 69604 men and women participating in one of the worlds' largest and longest running demographic and HIV cohorts, which enabled us to capture long-term trends in adult migration (i.e. 2005-2017) over a period when ART was scaled-up in South Africa. In addition, we analysed comprehensive data on the migration history of both male and female participants for close to 12-years, which helped us to not only measure levels and trends of migration, but also the effect of long-term time-varying covariates. Linking migrant characteristics with positive selection for incident migration will help disentangle the mechanisms behind the association between migration and HIV risk as the larger epidemiologic context changes in SSA. This effort leverages our previous work demonstrating that the risk of HIV acquisition conditional to migration increased by $70 \%(\mathrm{aOR}=1.69,95 \% \mathrm{Cl}: 2.33-2.14 ; P=35.0 \%)$ between $2000-$ 2017 [11]. We also used Andersen-Gill models to address frequent and recurrent migratory events per individual in the study area, adjusting for time-varying demographic and health covariates.

This study is not without limitations, with some participants not always being available at each successive round for HIV data collection being a challenge in the AHRI surveillance area, as in large and long-running studies elsewhere [30]. The lack of HIV ascertainment issue was noted by Vandormael and colleagues, who showed that over a 12-year period in the study area between 2005 and 2017, it is unlikely 
that HIV incidence rates were significantly affected by potential selection bias due to participants missing scheduled HIV tests [4]. Furthermore, we examined out-migration from the region and not in-migration, and thus did not explore concomitant mobility dynamics. However, given our large sample size and consistently high response rates in the AHRI household data collection surveys $(>99 \%)$, we believe that our results indicate a fairly balanced picture of the socio-demographic and health factors of migration among adults in rural KZN. We also show that the results from a complete case analysis (i.e., limiting the analysis to non-missing data of variables relevant variables), their socio-demographic characteristics (age and education status) and migration risk profiles were largely consistent, with estimates of missing covariate information (Supplementary Tables S2, S3). For additional sensitivity analyses, we fitted models for the hazard of migration by HIV status categories (i.e., variable accounting for the largest missingness), comparing the results of unknown HIV status with those HIV positive and negative. The results were comparable overall, with similarities in the aHR for ages 20-24 and 25-29 compared to 40+, i.e. $1.86 ; 3.33$ for those HIV positive, $1.91 ; 2.88$ for those with unknown HIV status, and 3.52 and 4.78 for those HIV negative. The magnitude and direction of effect of education status on migration was similar across the various HIV scenarios, particularly for those with secondary and tertiary level education, who had a higher aHR than those with primary education (Table S4-S6).

\section{Conclusions}

Our study provides evidence of the diverse migration characteristics of mobile men and women from a hyper-endemic community in South Africa. While the results highlight that migration remains a male domain, younger adults (i.e., both women and men), those unmarried and HIV positive were more likely to migrate, indicating the changing profile of migrants during an era of ART in an hyper-endemic community. Differentiated prevention and care interventions customized to the unique HIV risks and needs of mobile women and men are needed to reduce the risk of HIV acquisition and onward transmission among this highly vulnerable group.

\section{Abbreviations}

HIV-Human Immune Virus

ART-Antiretroviral Therapy

AIDS-Acquired Immune Deficiency Syndrome

PLHIV-People Living with HIV

SSA-Sub-Saharan Africa

UTT-Universal Test and Treat

AHRI-Africa Health Research Institute 
KZN-KwaZulu-Natal

PHC-Primary Health Care

CAB-Community Advisory Board

BREC-Biomedical Research Ethics Committee

PY-Person-Years

Cl-Confidence Interval

SEM-Standard Error of the Mean

IQR-Interquartile Range

HR-Hazard Ratio

AHR-Adjusted Hazard Ratio

\section{Declarations}

\section{Ethics approval and consent to participate}

Ethics permission for the demographic and HIV surveillance data collection and linkage was obtained from the University of KwaZulu-Natal biomedical research ethics committee (BREC) Ref. no. BE283/17. Administrative permissions for access to licensed raw data were granted by the AHRI Research Data Management Team. All methods were carried out in accordance with relevant guidelines and regulations and informed consent was obtained from all the study participants.

\section{Consent for publication}

No identifiable participant data (e.g., names or personal identifiers) are contained in this manuscript

\section{Acknowledgements}

The authors thank the community for their ongoing support and participation in the AHRI study site. They also thank the AHRI staff.

\section{Availability of data and materials}

Data used in this analysis are available to the public domain upon request from the AHRI repository https://data.africacentre.ac.za/index.php/auth/login/?destination

\section{Contributors}


The analysis was conducted by $A D$, with input from AT, AV and KG and approved by H-YK. The paper was written by $A D$ under the supervision of $A T, A V$ and $F T$. All authors approved the final draft.

\section{Funding}

This work was supported by two National Institute of Health (NIH) grants (R01HD084233 and R01Al124389). The Africa Health Research Institute's Demographic Surveillance Information System and Population Intervention Programme is funded by the Wellcome Trust (201433/Z/16/Z), and the South Africa Population Research Infrastructure Network (funded by the South African Department of Science and Technology and hosted by the South African Medical Research Council). The content is solely the responsibility of the authors and does not necessarily represent the official views of the funding bodies.

\section{Competing interests}

None declared.

\section{References}

1. UNAIDS. Global HIV and AIDS statistics 2019 Fact sheet. Global HIV/AIDs statistics, World AIDS day 2019 Fact Sheet 2019.

2. Tanser F, Bärnighausen T, Grapsa E, Zaidi J, Newell ML. High coverage of ART associated with decline in risk of HIV acquisition in rural KwaZulu-Natal, South Africa. Science. 2013 Feb 22;339(6122):966-71.

3. Bor J, Herbst AJ, Newell ML, Bärnighausen T. Increases in adult life expectancy in rural South Africa: valuing the scale-up of HIV treatment. Science. 2013 Feb 22;339(6122):961-5.

4. Vandormael A, Akullian A, Siedner M, de Oliveira T, Bärnighausen T, Tanser F. Declines in HIV incidence among men and women in a South African population-based cohort. Nature communications. 2019 Dec 2;10(1):1-0.

5. Lurie MN, Williams BG, Zuma K, Mkaya-Mwamburi D, Garnett GP, Sweat MD, Gittelsohn J, Karim SS. Who infects whom? HIV-1 concordance and discordance among migrant and non-migrant couples in South Africa. Aids. 2003 Oct 17;17(15):2245-52.

6. Voeten HA, Vissers DC, Gregson S, Zaba B, White RG, de Vlas SJ, Habbema JD. Strong association between in-migration and HIV prevalence in urban sub-Saharan Africa. Sexually transmitted diseases. 2010 Apr;37(4):240.

7. Cassels S, Jenness SM, Khanna AS. Conceptual framework and research methods for migration and HIV transmission dynamics. AIDS and Behavior. 2014 Dec;18(12):2302-13.

8. Larmarange J, Diallo MH, McGrath N, Iwuji C, Plazy M, Thiébaut R, Tanser F, Bärnighausen T, Pillay D, Dabis F, Orne-Gliemann J. The impact of population dynamics on the population HIV care cascade: results from the ANRS 12249 Treatment as Prevention trial in rural KwaZulu-Natal (South Africa). Journal of the International AIDS Society. 2018 Jul;21:e25128. 
9. Dzomba A, Tomita A, Vandormael A, Govender K, Tanser F. Effect of ART scale-up and female migration intensity on risk of HIV acquisition: results from a population-based cohort in KwaZuluNatal, South Africa. BMC public health. 2019 Dec;19(1):1-8.

10. Dzomba A, Tomita A, Govender K, Tanser F. Effects of migration on risky sexual behavior and HIV acquisition in South Africa: a systematic review and meta-analysis, 2000-2017. AIDS and Behavior. 2019 Jun;23(6):1396-430.

11. Tomita A, Vandormael AM, Bärnighausen T, de Oliveira T, Tanser F. Social disequilibrium and the risk of HIV acquisition: a multilevel study in rural KwaZulu-Natal Province, South Africa. Journal of acquired immune deficiency syndromes (1999). 2017 Jun 1;75(2):164.

12. Delany-Moretlwe S, Bello B, Kinross P, Oliff M, Chersich M, Kleinschmidt I, Rees H. HIV prevalence and risk in long-distance truck drivers in South Africa: a national cross-sectional survey. International journal of STD \& AIDS. 2014 May;25(6):428-38.

13. Brophy JE, Lessler J, Ssekubugu R, Kennedy CE, Chang LW, Kigozi G, Ndyanabo A, Kigozi G, Nalugoda F, Gray RH, Wawer MJ. Prevalence of Untreated HIV and Associated Risk Behaviors Among the Sexual Partners of Recent Migrants and Long-term Residents in Rakai, Uganda. JAIDS Journal of Acquired Immune Deficiency Syndromes. 2021 Nov 1;88(3):243-51.

14. Cassels S, Mwenda KM, Biney AA, Jenness SM. Is It the Timing? Short-Term Mobility and Coital Frequency in Agbogbloshie, Ghana. Archives of Sexual Behavior. 2021 Feb;50(2):589-600.

15. Laurence PA, Blower S. Mobility and circular migration in Lesotho: implications for transmission, treatment and control of a severe HIV epidemic. Journal of acquired immune deficiency syndromes (1999). 2015 Apr 15;68(5):604.

16. Lessells RJ, Mutevedzi PC, Cooke GS, Newell ML. Retention in HIV care for individuals not yet eligible for antiretroviral therapy: rural KwaZulu-Natal, South Africa. Journal of acquired immune deficiency syndromes (1999). 2011 Mar;56(3):e79.

17. Welaga P, Hosegood V, Weiner R, Hill C, Herbst K, Newell ML. Coming home to die? The association between migration and mortality in rural South Africa. BMC Public Health. 2009 Dec;9(1):1-8.

18. Taylor BS, Reyes E, Levine EA, Khan SZ, Garduno LS, Donastorg Y, Hammer SM, Brudney K, Hirsch JS. Patterns of geographic mobility predict barriers to engagement in HIV care and antiretroviral treatment adherence. AIDS patient care and STDs. 2014 Jun 1;28(6):284-95.

19. Camlin CS, Akullian A, Neilands TB, Getahun M, Bershteyn A, Ssali S, Geng E, Gandhi M, Cohen CR, Maeri I, Eyul P. Gendered dimensions of population mobility associated with HIV across three epidemics in rural Eastern Africa. Health \& place. 2019 May 1;57:339-51.

20. Posel D. Have migration patterns in post-apartheid South Africa changed?. Journal of Interdisciplinary Economics. 2004 Jul;15(3-4):277-92.

21. Posel D, Fairburn JA, Lund F. Labour migration and households: A reconsideration of the effects of the social pension on labour supply in South Africa. Economic modelling. 2006 Sep 1;23(5):836-53.

22. Valdano E, Okano JT, Colizza V, Mitonga HK, Blower S. Using mobile phone data to reveal risk flow networks underlying the HIV epidemic in Namibia. Nature communications. 2021 May 14;12(1):1-0. 
23. Colebunders R, Kenyon C. Behaviour, not mobility, is a risk factor for HIV. The Lancet HIV. 2015 Jun 1;2(6):e223-4.

24. Dobra A, Bärnighausen T, Vandormael A, Tanser F. Space-time migration patterns and risk of HIV acquisition in rural South Africa. AIDS (London, England). 2017 Jan 2;31(1):137.

25. Collinson MA. Striving against adversity: the dynamics of migration, health and poverty in rural South Africa. Global health action. 2010 Dec 1;3(1):5080.

26. Rasmussen DA, Wilkinson E, Vandormael A, Tanser F, Pillay D, Stadler T, de Oliveira T. External introductions helped drive and sustain the high incidence of HIV-1 in rural KwaZulu-Natal, South Africa. bioRxiv. 2017 Jan 1:119826.

27. Muhwava W, Hosegood V, Nyirenda M, Newell C, Herbst K, Newell M. Levels and determinants of population migration in rural KwaZulu-Natal, South Africa. Etude de la population africaine= African population studies. 2010.

28. McGrath N, Eaton JW, Newell ML, Hosegood V. Migration, sexual behaviour, and HIV risk: a general population cohort in rural South Africa. The lancet HIV. 2015 Jun 1;2(6):e252-9.

29. Marinda E, Simbayi L, Zuma K, Zungu N, Moyo S, Kondlo L, Jooste S, Nadol P, Igumbor E, Dietrich C, Briggs-Hagen M. Towards achieving the 90-90-90 HIV targets: results from the south African 2017 national HIV survey. BMC Public Health. 2020 Dec;20(1):1-2.

30. Clouse K, Vermund SH, Maskew M, Lurie MN, MacLeod W, Malete G, Carmona S, Sherman G, Fox MP. Mobility and clinic switching among postpartum women considered lost to HIV care in South Africa. Journal of acquired immune deficiency syndromes (1999). 2017 Apr 1;74(4):383.

31. Camlin CS, Cassels S, Seeley J. Bringing population mobility into focus to achieve HIV prevention goals. Journal of the International AIDS Society. 2018 Jul;21(Suppl Suppl 4).

32. Vandormael A, Newell ML, Bärnighausen T, Tanser F. Use of antiretroviral therapy in households and risk of HIV acquisition in rural KwaZulu-Natal, South Africa, 2004-12: a prospective cohort study. The Lancet Global Health. 2014 Apr 1;2(4):e209-15.

33. Channon M, Hosegood V, McGrath N. A longitudinal population-based analysis of relationship status and mortality in KwaZulu-Natal, South Africa 2001-2011. J Epidemiol Community Health. 2016 Jan 1;70(1):56-64.

34. Zaidi J, Grapsa E, Tanser F, Newell ML, Bärnighausen T. Dramatic increases in HIV prevalence after scale-up of antiretroviral treatment: a longitudinal population-based HIV surveillance study in rural kwazulu-natal. AIDS (London, England). 2013 Sep 10;27(14):2301.

35. Kim HY, Dobra A, Tanser F. Migration and first-year maternal mortality among HIV-positive postpartum women: A population-based longitudinal study in rural South Africa. PLoS medicine. 2020 Mar 31;17(3):e1003085.

36. Khumalo GE, Ntuli S, Lutge E, Mashamba-Thompson TP. Geo-Analysis: The Distribution of Community Health Workers in Relation to the HIV Prevalence in Kwazulu-Natal Province, South Africa. Preprint 
37. Gareta D, Baisley K, Mngomezulu T, Smit T, Khoza T, Nxumalo S, Dreyer J, Dube S, Majozi N, OrdingJesperson G, Ehlers E. Cohort profile update: Africa Centre Demographic Information System (ACDIS) and population-based HIV survey. International journal of epidemiology. 2021 Feb;50(1):33.

38. Larmarange J, Mossong J, Bärnighausen T, Newell ML. Participation dynamics in population-based longitudinal HIV surveillance in rural South Africa. PloS one. 2015 Apr 13;10(4):e0123345.

39. Lin H, Zelterman D. Modeling survival data: extending the Cox model. 2002.

40. Dzomba A. An analysis of the extent of migration and its impacts on the sending household in a rural area in South Africa (Doctoral dissertation).

41. De Haas H. Migration transitions. 2010.

42. Collinson MA, Wolff B, Tollman SM, Kahn K. Trends in internal labour migration from rural Limpopo Province, male risk behaviour, and implications for the spread of HIV/AIDS in rural South Africa. Journal of ethnic and migration studies. 2006 May 1;32(04):633-48.

43. Camlin CS, Snow RC, Hosegood V. Gendered patterns of migration in rural South Africa. Population, space and place. 2014 Aug;20(6):528-51.

44. Lindstrom DP. The occupational mobility of return migrants: Lessons from North America. InThe demography of Europe 2013 (pp. 175-205). Springer, Dordrecht.

45. Honwana AM. The Time of Youth: Work, Social Change. And Politics in Africa. 2012.

46. Niehaus I. Renegotiating masculinity in the South African Lowveld: narratives of male-male sex in labour compounds and in prisons. African Studies. 2002 Jul 1;61(1):77-97.

47. Bernays S, Lanyon C, Dlamini V, Ngwenya N, Seeley J. Being young and on the move in South Africa: how 'waithood'exacerbates HIV risks and disrupts the success of current HIV prevention interventions. Vulnerable Children and Youth Studies. 2020 Oct 1;15(4):368-78.

48. Lima VD, Druyts E, Montaner JS, Hogg RS. Regional and temporal trends in migration among people living with HIV/AIDS in British Columbia, 1993-2005. Canadian journal of public health. 2010 Jan;101(1):44-9.

49. Anglewicz P, VanLandingham M, Manda-Taylor L, Kohler HP. Health selection, migration, and HIV infection in Malawi. Demography. 2018 Jun 1;55(3):979-1007.

50. Grobler A, Cawood C, Khanyile D, Puren A, Kharsany AB. Progress of UNAIDS 90-90-90 targets in a district in KwaZulu-Natal, South Africa, with high HIV burden, in the HIPSS study: a household-based complex multilevel community survey. The Lancet HIV. 2017 Nov 1;4(11):e505-13.

51. Tanser F, Bärnighausen T, Vandormael A, Dobra A. HIV treatment cascade in migrants and mobile populations. Current Opinion in HIV and AIDS. 2015 Nov 1;10(6):430-8.

52. Candeias P, Alarcão V, Stefanovska-Petkovska M, Santos O, Virgolino A, Pintassilgo S, Pascoal PM, Costa AS, Machado FL. Reducing sexual and reproductive health inequities between natives and migrants: a Delphi consensus for sustainable cross-cultural healthcare pathways. Frontiers in public health. 2021 May 13;9:539. 
53. Vearey J. Moving forward: why responding to migration, mobility and HIV in South (ern) Africa is a public health priority. Journal of the International AIDS Society. 2018 Jul;21:e25137.

54. Cremin I, Morales F, Jewell BL, O'Reilly KR, Hallett TB. Seasonal PrEP for partners of migrant miners in southern Mozambique: a highly focused PrEP intervention. Journal of the International AIDS Society. 2015 Jul;18:19946.

55. Johnson CC, Kennedy C, Fonner V, Siegfried N, Figueroa C, Dalal S, Sands A, Baggaley R. Examining the effects of HIV self-testing compared to standard HIV testing services: a systematic review and meta-analysis. Journal of the International AIDS Society. 2017;20(1):21594.

56. Lippman SA, Lane T, Rabede O, Gilmore H, Chen YH, Mlotshwa N, Maleke K, Marr A, Mclntyre JA. High acceptability and increased HIV testing frequency following introduction of HIV self-testing and network distribution among South African MSM. Journal of acquired immune deficiency syndromes (1999). 2018 Mar 1;77(3):279.

57. Ritchwood TD, Selin A, Pettifor A, Lippman SA, Gilmore H, Kimaru L, Hove J, Wagner R, Twine R, Kahn K. HIV self-testing: South African young adults' recommendations for ease of use, test kit contents, accessibility, and supportive resources. BMC public health. 2019 Dec;19(1):1-0.

58. Giovenco D, Pettifor A, MacPhail C, Kahn K, Wagner R, Piwowar-Manning E, Wang J, Hughes JP. Assessing risk for HIV infection among adolescent girls in South Africa: an evaluation of the VOICE risk score (HPTN 068). Journal of the International AIDS Society. 2019 Jul;22(7):e25359.

\section{Tables}


Table 1

Mid-year estimates, residency status by sex and exposure year 2005-2017

\begin{tabular}{|c|c|c|c|c|c|c|c|c|}
\hline \multirow[t]{3}{*}{ Year } & \multicolumn{4}{|l|}{ Women } & \multicolumn{4}{|l|}{ Men } \\
\hline & \multicolumn{2}{|c|}{ Non-residents } & \multicolumn{2}{|c|}{ Residents } & \multicolumn{2}{|c|}{ Non-residents } & \multicolumn{2}{|c|}{ Residents } \\
\hline & $\mathrm{N}$ & $\%$ & $\mathrm{~N}$ & $\%$ & $\mathrm{~N}$ & $\%$ & $\mathrm{~N}$ & $\%$ \\
\hline 2005 & 13887 & $25.63 \%$ & 40304 & $74.37 \%$ & 15749 & $31.97 \%$ & 33514 & $68.03 \%$ \\
\hline 2006 & 14339 & $26.09 \%$ & 40618 & $73.91 \%$ & 16271 & $32.55 \%$ & 33711 & $67.45 \%$ \\
\hline 2007 & 14460 & $26.14 \%$ & 40868 & $73.86 \%$ & 16521 & $32.75 \%$ & 33922 & $67.25 \%$ \\
\hline 2008 & 14491 & $26.17 \%$ & 40887 & $73.83 \%$ & 16628 & $32.82 \%$ & 34037 & $67.18 \%$ \\
\hline 2009 & 14493 & $25.81 \%$ & 41663 & $74.19 \%$ & 16738 & $32.53 \%$ & 34738 & $67.48 \%$ \\
\hline 2010 & 14865 & $26.06 \%$ & 42180 & $73.94 \%$ & 17106 & $32.62 \%$ & 35331 & $67.38 \%$ \\
\hline 2011 & 15244 & $26.63 \%$ & 41945 & $73.37 \%$ & 17111 & $32.68 \%$ & 35244 & $67.32 \%$ \\
\hline 2012 & 15945 & $27.88 \%$ & 41256 & $72.12 \%$ & 17582 & $33.60 \%$ & 34752 & $66.40 \%$ \\
\hline 2013 & 15924 & $28.36 \%$ & 40226 & $71.64 \%$ & 17751 & $34.40 \%$ & 33850 & $65.60 \%$ \\
\hline 2014 & 16003 & $28.75 \%$ & 39654 & $71.25 \%$ & 18032 & $35.13 \%$ & 33299 & $64.87 \%$ \\
\hline 2015 & 16712 & $29.71 \%$ & 39532 & $70.29 \%$ & 18571 & $35.91 \%$ & 33147 & $66.33 \%$ \\
\hline 2016 & 16975 & $30.38 \%$ & 38907 & $69.62 \%$ & 18929 & $36.80 \%$ & 32513 & $63.20 \%$ \\
\hline 2017 & 18243 & $33.49 \%$ & 36229 & $66.51 \%$ & 20110 & $40.00 \%$ & 30164 & $60.00 \%$ \\
\hline
\end{tabular}


Table 2

Trends of migration rates by year (2005-2017)

\begin{tabular}{|c|c|c|c|c|}
\hline Year & $\begin{array}{l}\text { Number of out-migration } \\
\text { events }\end{array}$ & $\begin{array}{l}\text { Person- } \\
\text { years }\end{array}$ & $\begin{array}{l}\text { Migration rate (per } 100 \text { person- } \\
\text { years) }\end{array}$ & $95 \% \mathrm{Cl}$ \\
\hline 2005 & 3908 & 32340 & 12.08 & $\begin{array}{l}11.71- \\
12.47\end{array}$ \\
\hline 2006 & 3695 & 32604 & 11.33 & $\begin{array}{l}10.97- \\
11.70\end{array}$ \\
\hline 2007 & 3884 & 32733 & 11.87 & $\begin{array}{l}11.50- \\
12.24\end{array}$ \\
\hline 2008 & 3510 & 33120 & 10.60 & $\begin{array}{l}10.25- \\
10.95\end{array}$ \\
\hline 2009 & 3709 & 33771 & 10.98 & $\begin{array}{l}10.63- \\
11.34\end{array}$ \\
\hline 2010 & 4362 & 34262 & 12.73 & $\begin{array}{l}12.36- \\
13.11\end{array}$ \\
\hline 2011 & 4055 & 34355 & 11.80 & $\begin{array}{l}11.44- \\
12.17\end{array}$ \\
\hline 2012 & 4461 & 33860 & 13.17 & $\begin{array}{l}12.79- \\
13.56\end{array}$ \\
\hline 2013 & 3642 & 33271 & 10.95 & $\begin{array}{l}10.60- \\
11.31\end{array}$ \\
\hline 2014 & 3113 & 33003 & 9.43 & $9.11-9.77$ \\
\hline 2015 & 3088 & 32705 & 9.44 & $9.11-9.78$ \\
\hline 2016 & 3311 & 31501 & 10.51 & $\begin{array}{l}10.16- \\
10.87\end{array}$ \\
\hline 2017 & 3034 & 25510 & 11.89 & $\begin{array}{l}11.48- \\
12.32\end{array}$ \\
\hline
\end{tabular}


Table 3

Incidence of out-migration among resident adults from a rural South African cohort study ( $N=69604$ )

\begin{tabular}{|c|c|c|c|c|c|}
\hline & & $\begin{array}{l}\text { No. of } \\
\text { events }\end{array}$ & $\begin{array}{l}\text { Person-years at } \\
\text { risk }\end{array}$ & $\begin{array}{l}\text { Incidence rate } \\
\text { (per } 100 \text { person- } \\
\text { yrs) }\end{array}$ & $95 \% \mathrm{Cl}$ \\
\hline \multirow[t]{5}{*}{ Age category: } & $15-19 y$ & 11676 & 89098 & 13.10 & $\begin{array}{l}12.87- \\
13.34\end{array}$ \\
\hline & $20-24 y$ & 15810 & 69852 & 22.63 & $\begin{array}{l}22.28- \\
22.99\end{array}$ \\
\hline & $25-29 y$ & 8874 & 50003 & 17.75 & $17.38-$ \\
\hline & $30-34 y$ & 4374 & 37177 & 11.77 & $\begin{array}{l}11.42- \\
12.12-\end{array}$ \\
\hline & $\frac{35-39 y}{40 y+}$ & \begin{tabular}{|l|}
2404 \\
4634
\end{tabular} & \begin{tabular}{|l|}
29039 \\
47869
\end{tabular} & \begin{tabular}{|l|}
8.28 \\
3.13
\end{tabular} & $\frac{7.95-8.62}{3.04-3.23}$ \\
\hline \multirow[t]{2}{*}{ Sex: } & Male & 22782 & 172205 & 13.23 & $\begin{array}{l}13.06- \\
13.40\end{array}$ \\
\hline & Female & 24990 & 250833 & 9.96 & $\begin{array}{l}9.84- \\
10.09\end{array}$ \\
\hline \multirow[t]{4}{*}{$\begin{array}{l}\text { Educational } \\
\text { attainment: }\end{array}$} & None & 5264 & 77896 & 6.76 & $6.58-6.94$ \\
\hline & \begin{tabular}{|l} 
Primary $<=7 y$ \\
Secondary $8-12 y$
\end{tabular} & $\frac{2932}{30005}$ & \begin{tabular}{|l|}
50814 \\
206080
\end{tabular} & \begin{tabular}{|l|}
5.77 \\
14.56
\end{tabular} & $\begin{array}{l}5.56-5.98 \\
14.40- \\
14.73\end{array}$ \\
\hline & Tertiary $>12 y$ & 2025 & 19776 & 10.24 & $\begin{array}{l}9.80- \\
10.70\end{array}$ \\
\hline & $\begin{array}{l}\text { Unknown education } \\
\text { status }\end{array}$ & 7546 & 68472 & 11.02 & $\begin{array}{l}10.77- \\
11.27\end{array}$ \\
\hline \multirow[t]{3}{*}{ Marital status: } & Single & 36991 & 257152 & 14.38 & $\begin{array}{l}14.24- \\
14.53\end{array}$ \\
\hline & $\begin{array}{l}\text { Married } \\
\text { Divorced/Separated }\end{array}$ & $\begin{array}{l}1668 \\
624\end{array}$ & $\frac{64432}{39871}$ & $\frac{2.59}{157}$ & $\frac{2.47-2.72}{1.45-1.69}$ \\
\hline & $\begin{array}{l}\text { Unknown marital } \\
\text { status }\end{array}$ & 8489 & 61672 & 13.76 & $\begin{array}{l}13.47- \\
14.06\end{array}$ \\
\hline \multirow[t]{3}{*}{ HIV status: } & HIV- & 6446 & 155589 & 4.14 & $4.04-4.25$ \\
\hline & HIV+ & 4865 & 54879 & 8.86 & $8.62-9.12$ \\
\hline & HIV status unknown & 36461 & 212570 & 17.15 & $\begin{array}{l}16.98- \\
17.33\end{array}$ \\
\hline
\end{tabular}


Table 4

Determinants of out-migration in a rural South African cohort study ( $\mathrm{N}=69604$ )

\begin{tabular}{|c|c|c|c|c|}
\hline & Category & HR & SE $95 \% \mathrm{Cl}$ & \begin{tabular}{l|l|l} 
aHR & SE & $95 \% \mathrm{Cl}$
\end{tabular} \\
\hline Sex: [Female] & Male & $1.24^{\star \star \star}$ & $\begin{array}{c}0.011 .21- \\
1.26\end{array}$ & 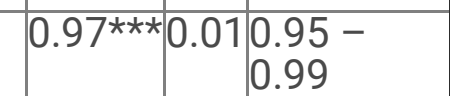 \\
\hline \multirow[t]{5}{*}{ Age category: $[\geq 40 y]$} & $15-19 y$ & $3.29 \star \star \star$ & $\times 0.06 \mid \begin{array}{l}3.17- \\
3.42\end{array}$ & $2.05^{\star \star \star} 0.051 .96-2.14$ \\
\hline & $20-24 y$ & $5.19 \star \star \star$ & \begin{tabular}{c|c}
0.11 & $5.71-$ \\
6.13
\end{tabular} & $\begin{array}{c}3.11^{\star \star \star} 0.06 \\
2.99- \\
3.24\end{array}$ \\
\hline & $25-29 y$ & $4.56^{\star \star \star}$ & $\begin{array}{c}0.09 \\
4.39- \\
4.74\end{array}$ & $2.30 \star \star \star 0.05\left[\begin{array}{l}2.20- \\
2.40\end{array}\right.$ \\
\hline & $30-34 y$ & $3.11^{\star \star \star}$ & $* 0.07 \mid \begin{array}{l}2.98- \\
3.25\end{array}$ & $\begin{array}{r}1.63^{\star \star \star} 0.04 \\
1.56- \\
1.72\end{array}$ \\
\hline & $35-39 y$ & $2.32^{\star \star \star}$ & 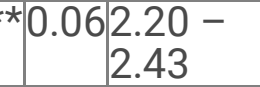 & $\begin{array}{r}1.38^{\star \star \star *} 0.04 \\
1.31- \\
1.45\end{array}$ \\
\hline \multirow[t]{4}{*}{$\begin{array}{l}\text { Educational attainment: } \\
\text { [Primary] }\end{array}$} & None & $1.13^{\star \star \star}$ & *0.03 $\begin{array}{c}1.08- \\
1.19\end{array}$ & \begin{tabular}{c|c|c}
$0.90 * \star \star$ & 0.02 & $0.85-$ \\
0.94
\end{tabular} \\
\hline & Secondary & $2.31^{\star \star \star}$ & $* 0.05 \mid \begin{array}{l}2.21- \\
2.40\end{array}$ & $1.26^{\star \star \star} 0.03 \frac{1.21-}{1.31}$ \\
\hline & Tertiary & $1.76^{\star \star \star}$ & $* 0.05 \frac{1.66-}{1.87}$ & 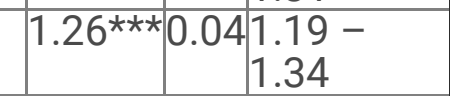 \\
\hline & $\begin{array}{l}\text { Unknown education } \\
\text { status }\end{array}$ & $1.63^{\star \star \star}$ & (0.04 $1.56-$ & \begin{tabular}{c|c|c}
$0.91^{\star \star \star *} 0.02$ & $0.87-8$ \\
0.96
\end{tabular} \\
\hline \multirow[t]{3}{*}{$\begin{array}{l}\text { Marital status: [Currently } \\
\text { married] }\end{array}$} & Single & $4.66^{\star \star \star}$ & \begin{tabular}{c|c}
0.13 & $4.42-$ \\
4.92
\end{tabular} & $2.28^{\star \star \star} 0.072 \begin{array}{l}2.15- \\
2.41\end{array}$ \\
\hline & Separated/Divorced & $0.64^{\star \star \star}$ & \begin{tabular}{c|}
0.03 \\
$0.58-$ \\
0.70
\end{tabular} & $0.86^{\star \star \star} 0.04 \mid \begin{array}{c}0.78- \\
0.95\end{array}$ \\
\hline & Unknown marital status & $4.45^{\star \star \star}$ & $=0.134 .20-$ & \begin{tabular}{c|c|c|}
$2.58^{* * *} 0.09$ & $2.42-$ \\
2.76
\end{tabular} \\
\hline \multirow[t]{2}{*}{ HIV status: [HIV-] } & HIV+ & $2.58^{\star \star \star}$ & $* 0.052 .48-$ & $2.44 * \star \star 0.052 \frac{2.35-}{2.54}-$ \\
\hline & Unknown HIV status & $4.65^{\star \star \star}$ & $\begin{array}{c}0.074 .53- \\
4.79\end{array}$ & $\begin{array}{c}4.15^{\star \star \star} 0.064 .03- \\
4.26\end{array}$ \\
\hline ART coverage & ART \% & $1.59 \star \star \star$ & $* 0.061 .49-$ & $\begin{array}{c}0.84^{\star \star *} 0.030 .79- \\
0.91\end{array}$ \\
\hline \multicolumn{5}{|c|}{$\begin{array}{l}* * * \mathrm{p}<0.05[\text { Reference category in brackets]. Abbreviations: aHR (Adjusted Hazard Ratio), ART } \\
\text { (Antiretroviral Therapy), Confidence intervals (CI), Hazard ratio (HR), HIV- (HIV Negative) HIV+ (HIV } \\
\text { positive) }\end{array}$} \\
\hline
\end{tabular}


Table 5

Determinants of out-migration in a rural area in South Africa by gender $(N=69604)$

\begin{tabular}{|c|c|c|c|c|c|}
\hline & Category & $95 \% \mathrm{Cl}$ & $95 \% \mathrm{Cl}$ & $95 \% \mathrm{Cl}$ & \begin{tabular}{|l|l|} 
IaHR & $\begin{array}{l}95 \% \\
\mathrm{Cl}\end{array}$ \\
\end{tabular} \\
\hline & & Female & & Male & \\
\hline & & $N=38372$ & & $N=30612$ & \\
\hline Age category: $[\geq 40 y]$ & $15-19 y$ & $\begin{array}{c}4.32^{* * *} 4.11- \\
4.55\end{array}$ & $2.32^{\star \star \star} \mid \begin{array}{l}2.18- \\
2.47\end{array}$ & $\begin{array}{c}2.18 * * * \mid \\
2.06- \\
2.31\end{array}$ & $\left.1.80^{\star \star \star}\right]_{-}^{1.68}$ \\
\hline & $20-24 y$ & $6.81^{\star \star \star} \frac{6.49-}{7.15}$ & $3.37^{\star \star \star} \mid \begin{array}{l}3.19- \\
3.57\end{array}$ & $\begin{aligned} 4.50 * \star \star & 4.27 \\
& -4.75\end{aligned}$ & $2.86^{\star * \star} \mid \begin{array}{r}1.92 \\
-\end{array}$ \\
\hline & $25-29 y$ & $\begin{array}{c}5.12^{\star \star \star} 4.86- \\
5.39\end{array}$ & $2.43^{\star \star \star} \frac{2}{2.29-} 2.58$ & $\begin{array}{r}3.61^{\star \star \star} 3.41- \\
3.83\end{array}$ & $2.17 * * \star 2.04$ \\
\hline & $30-34 y$ & 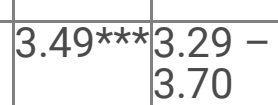 & $1.76^{\star \star \star} \mid \begin{array}{l}1.65- \\
1.88\end{array}$ & $\begin{aligned} & 2.48^{\star \star \star} 2.32- \\
& 2.64\end{aligned}$ & $1.52^{\star * \star} \mid .41$ \\
\hline & $35-39 y$ & $2.38^{\star \star \star} \mid \frac{2.22-}{2.55}-$ & $\begin{array}{c}1.39 * \star \star \\
1.29- \\
1.49\end{array}$ & $\begin{array}{r}2.07^{\star \star \star} \\
2.92- \\
2.22\end{array}$ & $1.37^{\star \star \star \star} \mid 1.63$ \\
\hline $\begin{array}{l}\text { Education status: } \\
\text { [Primary] }\end{array}$ & None & 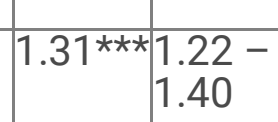 & \begin{tabular}{l|l}
0.92 & $0.86-$ \\
& 0.98
\end{tabular} & $\begin{aligned} & 0.94^{\star \star \star} 0.87- \\
& 1.00\end{aligned}$ & $\begin{array}{r}\frac{1.48}{0.85^{\star \star \star}} 0.80 \\
-\end{array}$ \\
\hline & Secondary & $\begin{aligned} & 2.72^{\star \star \star} 2.57- \\
& 2.88\end{aligned}$ & $1.26^{\star \star \star} \mid \begin{array}{l}1.19- \\
1.34\end{array}$ & $\begin{array}{c}1.82^{\star \star \star} \mid \\
1.72- \\
1.92\end{array}$ & $1.22^{\star \star *} \mid-1.16$ \\
\hline & Tertiary & $\begin{array}{r}2.11^{\star \star \star} \mid \\
1.95- \\
2.29\end{array}$ & $\begin{array}{c}1.29 \star \star \star \\
\\
1.40-19-\end{array}$ & $\begin{array}{c}1.40^{\star \star \star} \\
1.28- \\
1.53\end{array}$ & $\begin{array}{r}\mid 1.29 \\
1.20^{* * *} \mid .09 \\
-\end{array}$ \\
\hline & $\begin{array}{l}\text { Unknown } \\
\text { Educational status }\end{array}$ & $\begin{array}{l}1.87^{\star \star \star} \mid \\
2.75- \\
2.01\end{array}$ & $0.88^{\star \star \star} \mid \begin{array}{l}0.82- \\
0.94\end{array}$ & \begin{tabular}{l|l}
$1.35^{\star \star}$ & $1.27-$ \\
& 1.44
\end{tabular} & $0.93^{\star \star} \mid$\begin{tabular}{l|l}
1.31 \\
-
\end{tabular} \\
\hline $\begin{array}{l}\text { Marital status: [Currently } \\
\text { Married] }\end{array}$ & Single & $5.18^{\star \star \star} 4.81-$ & $\begin{array}{r}2.49^{\star \star \star} 2 \\
2.30- \\
2.69\end{array}$ & $\begin{array}{c}3.97^{\star \star \star} 3.68- \\
4.28\end{array}$ & $2.04^{\star \star \star} \mid \begin{array}{l}0.99 \\
--\end{array}$ \\
\hline & Separated/Divorced & $0.72^{\star \star \star} \mid \begin{array}{l}0.64- \\
0.80\end{array}$ & \begin{tabular}{l|l}
0.96 & $0.86-$ \\
& 1.08
\end{tabular} & $\begin{array}{l}0.77- \\
1.21\end{array}$ & 0.86 \\
\hline & $\begin{array}{l}\text { Unknown marital } \\
\text { status }\end{array}$ & $5.98^{\star \star \star}\left[\begin{array}{l}5.53- \\
6.47\end{array}\right.$ & $3.15^{\star \star \star} \frac{2.88-}{3.45}$ & $\begin{aligned} & 3.03^{\star \star \star} 2.78- \\
& 3.29\end{aligned}$ & $\begin{array}{r}1.35 \\
2.00^{* * \star} \mid 1.82 \\
-\end{array}$ \\
\hline HIV status: [HIV-] & HIV+ & $2.79 \star \star \star 2.66-$ & $2.44^{\star \star \star} \mid \frac{2.33-}{2.57}-$ & $\begin{array}{l}2.26^{\star \star \star} 2.11- \\
2.42\end{array}$ & $2.54^{\star \star \star} \mid-2.36$ \\
\hline & Unknown HIV status & 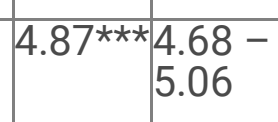 & $\begin{array}{c}4.18^{\star \star \star} 4.03- \\
4.34\end{array}$ & $\begin{array}{c}4.23^{\star \star \star} 4.06- \\
4.41\end{array}$ & $4.05^{\star \star \star} \mid \begin{array}{l}3.89 \\
- \\
1\end{array} 20$ \\
\hline ART coverage & ART\% & $\begin{aligned} & 2.64 * \star \star 2.44- \\
& 2.87\end{aligned}$ & $\begin{array}{c}0.91 \star \star \star \\
0.83- \\
0.99\end{array}$ & $\begin{array}{l}0.88^{-} \\
1.07\end{array}$ & \begin{tabular}{|l|}
4.23 \\
$0.73^{\star \star \star}$ \\
\\
\\
\\
0.66 \\
0.82
\end{tabular} \\
\hline
\end{tabular}

Figures 


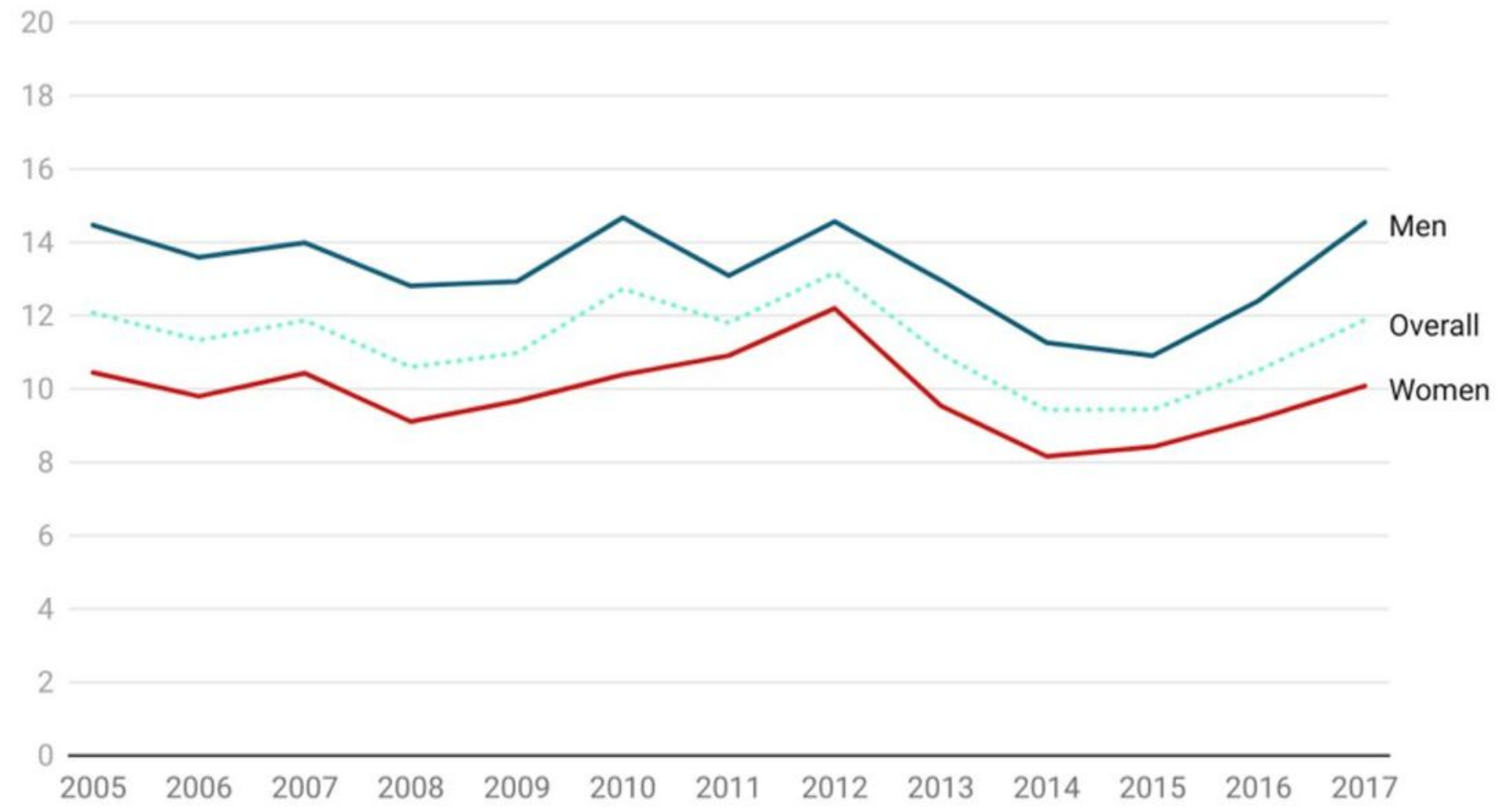

\section{Figure 1}

Trends of out-migration rates from a rural area in South Africa: 2005-2017 


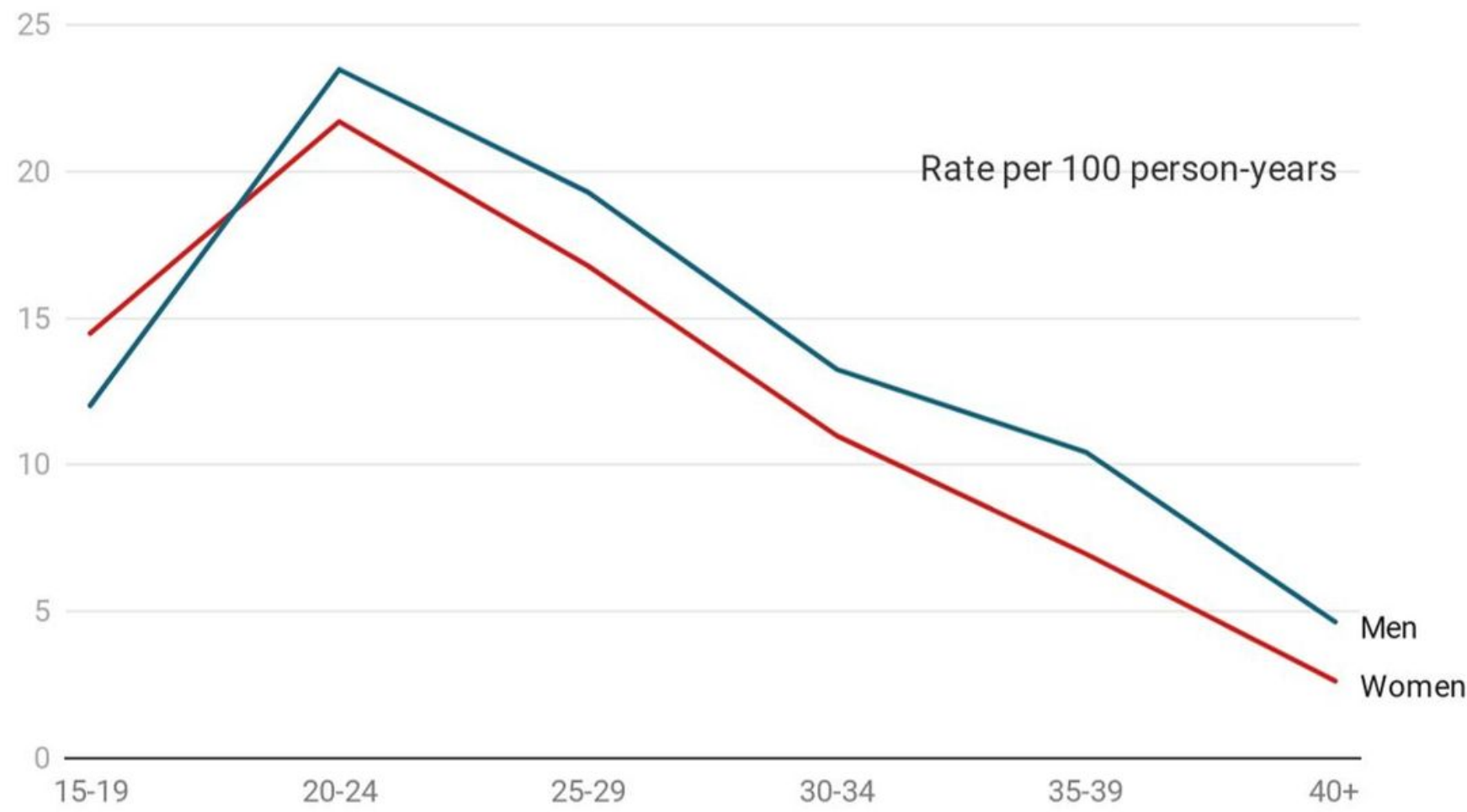

Figure 2

Migration rates by age and sex for the 2005-2017

\section{Supplementary Files}

This is a list of supplementary files associated with this preprint. Click to download.

- Supplementarytables.docx 